\title{
The development of emotional and behavioral self-regulation and their effects on academic achievement in childhood
}

\author{
Ashenafi Kassahun Edossa, Ulrich Schroeders, \\ Sabine Weinert, and Cordula Artelt
}

\begin{abstract}
Self-regulation is an essential ability of children to cope with various developmental challenges. This study examines the developmental interplay between emotional and behavioral self-regulation during childhood and the relationship with academic achievement using data from the longitudinal Millennium Cohort Study (UK). Using cross-lagged panel analyses, we found that emotional and behavioral selfregulation were separate and stable constructs. In addition, both emotional and behavioral self-regulation had positive cross-lagged effects from ages 3 to 7 . At an early developmental stage (ages 3 to 5), emotional regulation affected behavioral regulation more strongly than later developmental stages. However, the difference between the reciprocal effects was small from ages 5 to 7 . Moreover, behavioral regulation during the third year of primary education (age 7) had a substantial and positive effect on teachers' evaluations of educational achievement during the last year of primary school (age II). In contrast, emotional self-regulation only had a small indirect and positive effect via behavioral self-regulation. The current study suggests the structure of self-regulation was multidimensional and its facets are mutually dependent in the child's development. In order to gain a complete picture of the development of self-regulation and its effect on educational achievement, the facets emotional and behavioral regulation should both be studied in concert.
\end{abstract}

\section{Keywords}

Self-regulation, emotional regulation, behavioral regulation, academic achievement, child development

Self-regulation is the ability of individuals to adjust their cognition, emotion, and behavior in order to meet both intrinsic and extrinsic demands (McClelland, Ponitz, Messersmith, \& Tominey, 2010). The acquisition of these regulatory skills is an important developmental construct over the lifespan, especially with regard to early childhood (Blair \& Diamond, 2008) and academic achievement (Blair, 2002; Gestsdottir et al., 2014; Valiente, Lemery-Chalfant, \& Swanson, 2010). A plethora of factors influence self-regulation, including neurophysiological maturation, parenting, and peer socialization. Accordingly, numerous studies examining the development of behavioral and emotional self-regulation during childhood have focused on external social aspects, most prominently parenting styles (Eisenberg, Chang, Ma, \& Huang, 2009). Although external social variables are important to the development of self-regulation, children can have their own agency in the sense that the development of one facet of self-regulation might enhance the development of other facets (Cicchetti \& Tucker, 1994; Demetriou, 2000). However, little is known about the internal structure of self-regulation and its development over time. The present study investigated the relationship between emotional and behavioral self-regulation across childhood as well as quantified the effect of these constructs on academic achievement using data from the Millennium Cohort Study (MCS, UK).

\section{Emotional and Behavioral Self-regulation}

Researchers conceptualize self-regulation and its facets differently. The operationalization of emotional regulation in the present study is in line with Thomson's (1994, p. 27) definition of "monitoring, evaluating, and modifying emotional reactions, especially their intensive and temporal features, to accomplish one's goal." Rothbart and Bates (2006) further differentiated between the activation (emotionality) and the regulation component of emotion (emotional regulation). However, Cole, Martin, and Dennis (2004, p. 319) argued that it is difficult to distinguish between emotionality and emotional regulation because emotion is "inherently regulatory." Behavioral regulation is understood as the ability to monitor attention and inhibit behavior in favor of goal achievement (Blair, 2002; McClelland et al., 2010). This conceptualization of behavioral regulation, which we used in the present context, is closely related to effortful control, which is defined as "the efficiency of executive attention, including the ability to inhibit a dominant response and/or to activate a subdominant response, to plan, and to detect errors" (Rothbart \& Bates, 2006, p. 129). Self-regulation researchers who focus on cognitive development frequently use the term executive function as a set of cognitive skills to deliberately manage thought and action (Blair, 2002; Jacob \& Parkinson, 2015; McClelland et al., 2007). In connection with the cognitive aspect of executive function, a third component of self-regulation can be defined:

University of Bamberg, Germany

Corresponding author:

Ashenafi Kassahun Edossa, University of Bamberg, Feldkirchenstr. 21, Bamberg, 96052, Germany.

Email: ashenafi-kassahun.edossa@uni-bamberg.de 
Table I. Testing for Longitudinal Measurement Invariance with Continuous and Categorical Data.

\begin{tabular}{|c|c|c|c|c|}
\hline $\begin{array}{l}\text { Continuous } \\
\text { variables }\end{array}$ & $\begin{array}{l}\text { Factor } \\
\text { Loadings }\end{array}$ & Intercepts & $\begin{array}{l}\text { Residual } \\
\text { Variances }\end{array}$ & $\begin{array}{l}\text { Factor } \\
\text { Means }\end{array}$ \\
\hline Configural invariance & $*$ & $*$ & $*$ & Fixed at 0 \\
\hline Weak invariance & Fixed & $*$ & $*$ & Fixed at 0 \\
\hline Strong invariance & Fixed & Fixed & $*$ & Fixed at $0 / *$ \\
\hline Strict invariance & Fixed & Fixed & Fixed & Fixed at $0 / *$ \\
\hline Categorical variables & $\begin{array}{l}\text { Factor } \\
\text { loadings }\end{array}$ & Thresholds & $\begin{array}{l}\text { Residual } \\
\quad \text { variances }\end{array}$ & $\begin{array}{l}\text { Factor } \\
\text { means }\end{array}$ \\
\hline Configural invariance & $(*$ & $*)$ & Fixed at I & Fixed at 0 \\
\hline Strong invariance & (Fixed & Fixed) & Fixed at $1 / *$ & Fixed at $0 / *$ \\
\hline Strict invariance & (Fixed & Fixed) & Fixed at I & Fixed at $0 / *$ \\
\hline
\end{tabular}

Note. The asterisk $(*)$ indicates that the parameter is freely estimated. Fixed $=$ the parameter is fixed to equity over time points; Fixed at $\mathrm{I}=$ the residual variances are fixed to $\mathrm{I}$ at all time points; Fixed at $0=$ factor means are fixed at 0 at all time points. Fixed at $0 / *=$ factor means are fixed at 0 at the first time point and freely estimated at the other time points. Fixed at $\mathrm{I} / *=$ the residual variances are fixed to $I$ at the first time point and freely estimated at the other time points. Parameters in parentheses need to be varied in tandem.

metacognition, which reflects the knowledge about cognition and its regulation (Flavell, 1979).

\section{Structure of Self-regulation}

In the self-regulation literature, two major competing theories concern the structure of self-regulation (Cicchetti \& Tucker, 1994; Muraven \& Baumeister, 2000). The first theory assumes that selfregulation is a domain-general ability without clear differentiation between components such as emotional and behavioral selfregulation (Berkman, Graham, \& Fisher, 2012; Kopp, 1982; Muraven \& Baumeister, 2000). From this perspective, "similar processes are common across all domains of self-regulation" (Heatherton, 2011, p. 379), and self-regulation is considered as a limited resource shared across the behavioral, emotional, and cognitive domains (Berkman, Graham, \& Fisher, 2012; Muraven \& Baumeister, 2000). A longitudinal study conducted among 646 children from age 4 to 12 by Raffaelli, Crockett, and Shen (2005) has supported this argument empirically, leading to the conclusion that a single factor is parsimonious and sufficient. However, the reported model fits (see Table 1, p. 65) essentially suggested multidimensionality except for the first time point (age 4 or 5). Their notion of uni-dimensionality is based on the high factor correlations between emotional, behavioral, and self-regulation, but the direct model comparisons clearly advocate for multidimensionality. In the second more prominent theory, self-regulation is conceptualized as a multidimensional construct that is composed of emotional, behavioral, and cognitive self-regulation with specific developmental trajectories (Cicchetti \& Tucker, 1994; McClelland et al., 2010; Schields, Cicchetti, \& Ryan, 1994). More precisely, "emotional and behavioral regulatory processes, although interrelated, may be expressions of developmentally distinct systems" (Schields et al., 1994, p. 61). Related to this view, Hammer, Melhuish, and Howard (2015) tested whether the cognitive, emotional, and behavioral facets of self-regulation are developmentally unified or separated constructs across two cohorts (from birth: $n=5,107$; from kindergarten: $n=4,981$ ). Their results supported the perspective that facets are related but distinct self-regulatory systems.
Similarly, cross-sectional studies have replicated the multidimensional structure of self-regulation (Kalpidou, Power, Cherry, \& Gottfried, 2004; Schields et al., 1994). The notion that the structure of self-regulation may vary with age also exists. In line with the functional specialization of the neural system and the adaptation of the child to a changing environment, self-regulation might become more differentiated throughout development (Johnson, 2011). Research on self-regulation focusing on executive functioning consistently finds support for age-related differentiation processes (Zelazo \& Carlson, 2012).

\section{Developmental Interplay between Emotional and Behavioral Regulation}

Assuming that self-regulation is a multidimensional construct, developmental theories have hypothesized that a developmental interplay exists between emotional and behavioral regulation within the child (Campos, Frankel, \& Camras, 2004; Cicchetti \& Tucker, 1994). From a neurobiological perspective (Blair, 2002; Blair \& Diamond, 2008), a reciprocal effect is created based on the neural interconnectivity between the different brain areas associated with emotional (the amygdala in the limbic system) and behavioral (prefrontal cortex) regulation. Given the high neural plasticity that exists during early childhood, experience also shapes this neural connection (Blair, 2002; Cicchetti \& Toth, 1998). Children who are more able to regulate their behavioral repertoire should also be more able to regulate their emotions more flexibly and efficiently (Campos et al., 2004; Carver \& Scheier, 2012; Eisenberg \& Spinrad, 2004). With respect to the strength and the direction of effects between the components of the self-regulatory system, Blair (2002) indicated that the development of emotional regulation might have a stronger effect on behavioral regulation than the effect behavioral regulation has on emotional regulation. Although Blair (2002, p. 114) has not specified the causal relationship between emotional and behavioral self-regulation (i.e., the regulation of attention and behavioral inhibition) in detail, he emphasized that "the developmental maturational primacy of the limbic structures associated with emotion" (p. 114) is crucial for behavioral self-regulation. To our knowledge, no sound empirical evidence exists regarding the direction of the effects between emotional and behavioral regulation. As a consequence, it seems promising to study emotional and behavioral self-regulation processes in concert in order to examine the structural stability and reciprocal effects over time (Schields et al., 1994) as well as the directionality of their relationship.

\section{Stability of Emotional and Behavioral Regulation}

Although self-regulation is a relatively stable construct, children's self-regulatory skills develop from infantile self-soothing behaviors to toddlerhood reorienting and compliance. In later years, these behaviors include preschoolers' increments in the delay of gratification and the continued advancement of these skills and abilities (Kopp, 1982). Empirical evidence indicates that individual differences in self-regulation become fairly stable after the first year of life (Eisenberg, Spinrad, \& Eggum, 2010). For instance, Murphy, Eisenberg, Fabes, Shepard, and Guthrie (1999) followed children from ages 4 to 12 to examine the stability of their individual differences in self-regulation. They found correlations ranging from .54 to .78 for parental reports of negative emotionality and from 
.69 to .71 for positive emotionality at a manifest level at different time points. Similarly, Raffaelli et al. (2005) showed that parental reports of their children's emotional and behavioral regulation were fairly stable from early childhood to early adolescence. In summary, although different operationalizations of self-regulation and disparate methodological approaches have been used, the high stability of the facets of self-regulation is well established. Nevertheless, a growing body of literature has addressed the malleability (to some degree) of self-regulatory skills depending on the personal characteristics such as a critical period that can individually vary, the initial self-regulatory ability, or the family background of the child (Blair, 2016; Schmitt, McClelland, Tominey, \& Acock, 2015). From a theoretical perspective, the change can be epigenetically attributed to the neural connectivity plasticity in response to experience (Blair, 2002; Blair \& Diamond, 2008).

\section{Emotional and Behavioral Self-regulation and Academic Achievement}

Self-regulation is positively associated with academic achievement because it helps children to focus, monitor, and control their learning activities, follow classroom instructions, and solve academic problems (Blair, 2002; McClelland et al., 2007; Valiente et al., 2010). The association between the early development of behavioral regulation and later academic achievement has been demonstrated several times, even for different educational systems (Gestsdottir et al., 2014; McClelland et al., 2007). In addition, emotional regulation is positively associated with academic achievement in the sense that it promotes maintaining an optimal emotional arousal level that is needed for learning (Blair, 2002; Ng, Tamis-LeMonda, Yoshikawa, \& Sze, 2015). Furthermore, the development of emotional regulation can also affect academic achievement through behavioral regulation. For instance, Howse, Calkins, Anastopoulos, Keane, and Shelton (2003) examined how behavioral regulation mediates the relationship between emotional regulation and academic achievement in a longitudinal study and found that children with efficacious emotional regulation abilities had higher achievement scores. However, this relationship was mediated by behavioral regulation ability among children in kindergarten. In addition, a body of literature suggests that other mediators such as student-child relationship, class participation, and school liking exist (Diaz et al., 2015; Valiente, Lemery-Chalfant, \& Castro, 2007; Valiente, Lemery-Chalfant, Swanson, \& Reiser, 2008).

Despite the substantive body of literature linking self-regulation to academic achievement, this does not imply any causal relationship. In their meta-analysis, Jacob and Parkinson (2015, p. 530) concluded that there is "no compelling evidence that these associations are causal," because only a few studies have controlled for the child's family background or general cognitive ability. They also argue that intervention studies often include activities that improve both self-regulation and academic achievement; thus, the associations between self-regulation and academic achievement are not necessarily causal. This criticism is amplified by the fact that socioeconomic status (SES) is also positively associated with selfregulation (Lengua et al., 2015; Raver, Blair, Willoughby, \& Family Life Project Key Investigators, 2013) and academic achievement (Lengua et al., 2015). SES affects child development, particularly self-regulation and academic achievement, through the material and psychosocial context of the family. Thus, SES affects the quality of stimulation, care, and academic support given to children. In families with low SES, the poverty might induce stressors and hamper stable social relationships (e.g., frequent moves), which finally could affect the neural connectivity in the child's brain (Blair \& Raver, 2012). As a consequence, Valiente and colleagues (2008) have suggested the importance of including SES in studies focusing on the relationship between self-regulatory ability and academic achievement.

\section{The Present Study}

Conflicting theories and mixed empirical results exist regarding the structure of self-regulation. Although the majority of studies have advocated a multidimensional perspective (McClelland et al., 2010; Schields et al., 1994), the uni- vs. multidimensional perspectives have not been thoroughly tested within the context of a longitudinal study. Therefore, we first examined the internal structure of selfregulation (i.e., a uni- vs. two-dimensional model). Because the latter model best describes the data, we investigated a) the stability within the facets (i.e., behavioral regulation and emotional regulation) and b) the development of effects across the facets throughout childhood via a cross-lagged panel analyses. Finally, we predicted academic achievement at the end of primary education (as measured via teacher evaluations) using emotional and behavioral regulation in childhood. We assumed that behavioral regulation enhances academic achievement because monitoring attention and engagement is crucial for knowledge and skill acquisition, whereas emotional regulation only indirectly fosters academic achievement through behavioral regulation.

Within the framework of structural equation modeling (SEM), a cross-lagged panel analysis was specified using three measurement time points (ages 3, 5, and 7). Cross-lagged model analysis is especially useful when investigating the developmental interplay between constructs (Selig \& Little, 2012). Prior to examining the stability and cross-facet effects, we checked for the measurement invariance of emotional and behavioral self-regulation using a longitudinal confirmatory factor analysis, this procedure is important for making valid statements across time points. Only strong measurement invariance enables us to attribute potential changes to theoretical constructs and not methodological artifacts (Little, Preacher, Selig, \& Card, 2007; Selig \& Little, 2012). In addition, academic achievement at the end of primary education (age 11) was predicted using emotional and behavioral self-regulation (age 7). Moreover, the mediation of behavioral regulation at age 7 was analyzed. All analyses were conducted twice: with and without controlling for SES.

\section{Method}

\section{Participants and Procedure}

The Millennium Cohort Study is a longitudinal birth cohort study that follows the lives of children (51\% boys) born in 2000 and 2001 in the United Kingdom (Hansen, 2014). Cluster (electoral wards) sampling with disproportionate stratification was used to adequately represent ethnic minorities (Plewis, 2007). In terms of ethnic proportion, $82 \%$ were White, $4.8 \%$ were Pakistani, $2.5 \%$ were Indian, $2 \%$ were Bangladeshi, $2 \%$ were Black African, $1.3 \%$ were Black Caribbean, and $3 \%$ of the cohort members were of mixed race. Based on the National Statistics Socioeconomic Classification (NS-SEC), the highest occupational status within a family was 
Table 2. Descriptive Statistics of the Self-Regulation Items at age 3, 5, and 7, and Academic Achievement at age II.

\begin{tabular}{|c|c|c|c|c|c|c|c|c|c|c|c|c|c|}
\hline \multirow[b]{2}{*}{ Items } & \multicolumn{3}{|c|}{ Age 3} & \multicolumn{3}{|c|}{ Age 5} & \multicolumn{3}{|c|}{ Age 7} & & \multicolumn{3}{|c|}{ Age II } \\
\hline & $n$ & M & $S D$ & $n$ & M & $S D$ & $n$ & M & $S D$ & & $n$ & M & $S D$ \\
\hline Emotional regulation & & & & & & & & & & Academic achievement & & & \\
\hline Item I & 14,532 & 2.07 & 0.75 & $|3,19|$ & 2.39 & 0.72 & 12,180 & 2.40 & 0.72 & Maths & 6,735 & 3.43 & 1.01 \\
\hline Item 2 & 14,585 & 1.88 & 0.72 & 13,254 & 2.02 & 0.73 & 12,235 & 2.07 & 0.74 & English & 6,751 & 3.36 & 1.01 \\
\hline Item 3 & 14,472 & 2.04 & 0.73 & 13,199 & 2.21 & 0.71 & 12,203 & 2.20 & 0.72 & Science & 6,730 & 3.39 & 0.86 \\
\hline Item 4 & 14,019 & 2.08 & 0.72 & 13,017 & 2.31 & 0.69 & $12,10 \mid$ & 2.32 & 0.70 & Information and communication technology & 6,733 & 3.39 & 0.73 \\
\hline \multicolumn{14}{|c|}{ Behavioral regulation } \\
\hline Item I & $|4,10|$ & 2.24 & 0.62 & 13,014 & 2.25 & 0.61 & 12,079 & 2.24 & 0.63 & & & & \\
\hline Item 2 & 14,506 & 2.62 & 0.54 & 13,268 & 2.71 & 0.48 & 12,276 & 2.71 & 0.48 & & & & \\
\hline Item 3 & 14,170 & 2.13 & 0.62 & 13,138 & 2.30 & 0.63 & 12,155 & 2.29 & 0.66 & & & & \\
\hline Item 4 & 13,534 & 2.03 & 0.61 & 12,929 & 2.11 & 0.57 & 12,100 & 2.15 & 0.59 & & & & \\
\hline
\end{tabular}

Note. Both emotional and behavioral regulation ranges from I (not true) to 3 (certainly true). The ranges of academic achievement were from I (well below average) to 4 (well above average).

coded as managerial and professional (44.2\%), intermediate occupation $(14.3 \%)$, small employers $(8.2 \%)$, lower supervisory and technical occupation $(9 \%)$, or semi-routine and routine occupations (24.4\%). Approximately $36 \%$ of the mothers held a first degree or higher, and $46 \%$ held a General Certificate of Secondary Education to A level. However, $13 \%$ of the mothers had no education qualifications. The family income quantiles (based on a modified version of the Organization for Economic Cooperation and Development equivalence scale) were 1 st $(21.7 \%)$, 2nd (22\%), 3rd (19\%), 4th $(18.9 \%)$, and 5th (17.8\%) from lowest to highest level.

Children's ages across the different sweeps (Hansen, 2014) were 9 months $\left(n_{1}=18,552\right), 3$ years $\left(n_{2}=15,590\right), 5$ years $\left(n_{3}=\right.$ $15,246), 7$ years $\left(n_{4}=13,857\right)$, and 11 years $\left(n_{5}=13,287\right)$. The development of self-regulation was investigated from the second sweep ( 3 years) when the assessment of self-regulation began to the third sweep ( 7 years). The second sweep ( 5 years) denotes the period when children start their primary school education. Academic achievement was assessed during the last sweep (age 11) at the end of primary school. In the case of twins and multiple births in a family, we analyzed the data of the first child to avoid clustered data structures. Approximately $97 \%$ of the participants who rated children's self-regulation were their natural mothers.

\section{Measures}

Emotional Regulation (ER). Emotional regulation was measured at ages 3, 5, and 7 using the Emotional Dysregulation (ED) scale of the Child Social Behavior Questionnaire (CSBQ), which is based on the Adaptive Social Behavior Inventory (Hogan, Scott, \& Bauer, 1992). The CSBQ was validated in England (Sammons et al., 2004) and Northern Ireland (Melhuish et al., 2004). Parents were asked to give their answers based on their child's behavior over the last six months with regard to the following five items: "The child shows mood swings" (ER1, see the descriptive statistics in Table 2), "gets over excited" (ER2), "gets easily frustrated" (ER3), "acts impulsively" (ER4) and "gets over being upset quickly" (ER5). The response categories were "Not True" (1), "True" (2), and "Certainly True" (3). The last item was discarded because it consistently showed a low factor loading at the three time points. The items were worded similarly over the three time points.

Behavioral Regulation (BR). Behavioral regulation was measured at ages 3, 5, and 7 using four items. The two items, "The child persists in the face of difficult tasks" (BR1, see the descriptive statistics in Table 2) and "moves to a new activity after finishing a task" (BR2) were originally taken from the Independence and Self-Regulation (ISR) scale, a sub-domain of the CSBQ (Hogan et al., 1992). The remaining two items "sees tasks through to the end" (BR3) and "can stop and think before acting"(BR4) were adopted from the Strength and Difficulties Questionnaire (SDQ, Goodman \& Goodman, 2009), which was developed and validated in the UK. The SDQ is a behavioral screening questionnaire, and it has been used frequently to assess behavioral regulation (e.g., Vernon-Feagans, Willoughby, Garrett-Peters, \& The Family Life Project Key Investigators, 2016). Similar to emotional regulation, parents rated their children's behavioral regulation on a threepoint scale.

Academic Achievement (AA). The academic achievement of the children was assessed at age 11 (sweep 5) with teachers' evaluations of their performance in the following domains: (a) English language; (b) mathematics; (c) science; (d) information and communication technology. We chose these key subjects out of the total seven, excluding arts and design, music, and physical education. Teacher evaluations were provided on a five-point scale (well below average, below average, average, above average, well above average), with higher values indicating better performance. Children in the sample were distributed in 7,430 classes.

Socioeconomic status (SES). The SES of the family was included as a control variable. SES was assessed using three indicators; the highest occupation status of the parents measured by the National Statistics Socioeconomic Classification (NS-SEC), a primary social classification in the UK based on the Goldthorpe schema of five categories ranging from managerial and professional to semiroutine and routine workers (Rose, Pevalin, \& O'Reilly, 2005), the highest educational status of the parents, and household income.

\section{Statistical Analyses}

All analyses were conducted using R (R Development Core Team, 2011) and the R package lavaan (Rosseel et al., 2012). The weighted least squares mean and variance-adjusted (WLSMV) estimator was used for all models including the cross-lagged panel analysis. In a simulation study, Beauducel and Herzberg (2006; see also Rhemtulla, Brosseau-Liard, \& Savalei, 2012) showed the 


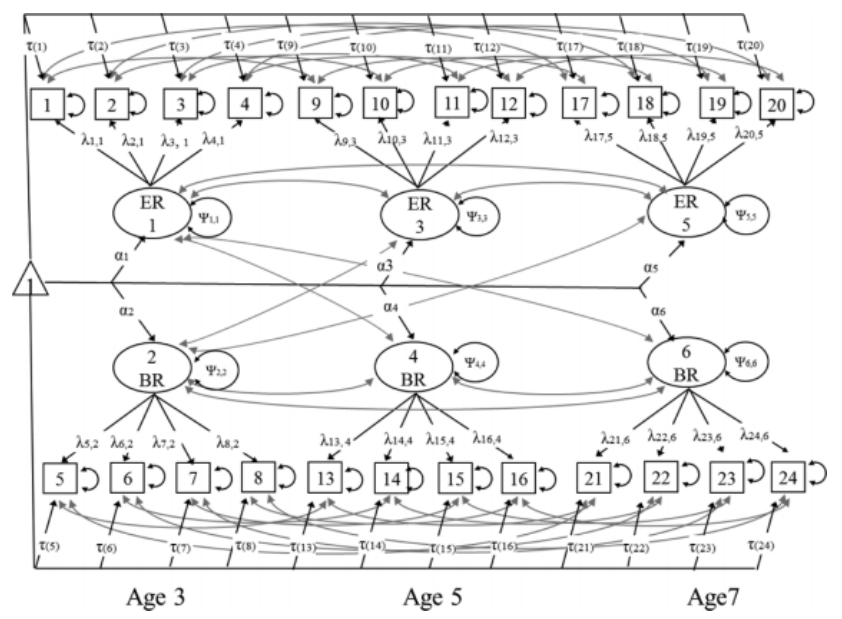

Figure I. Longitudinal measurement invariance testing. Note. $\mathrm{ER}=$ emotional regulation, $\mathrm{BR}=$ behavioral regulation.

superiority of the WLSMV estimator for categorical data compared with the maximum likelihood estimator in terms of both the model rejection rates and the appropriate estimation of factor loadings. This notion holds true especially with fewer than five response categories such as the current case of only three categories. The following comparative fit index $(\mathrm{CFI})$ and the root mean square error of approximation (RMSEA) values were used to indicate an acceptable model fit: $\mathrm{CFI} \geq .95$, RMSEA $\leq .08$ (Hu \& Bentler, 1999).

Measurement Invariance. A longitudinal CFA (see Figure 1) was applied to examine the comparability of the measurement instruments for emotional and behavioral regulation across the three time points (ages 3, 5, and 7). Specifically, a longitudinal measurement invariance approach (Little et al., 2007), which is superior to the cross-sectional approach of multi-group confirmatory analysis, was used. Thus, all measurement points were included in one model in which the residuals of similarly worded items were allowed to covary across time points (Little et al., 2007).

Because all emotional and behavioral self-regulation items were answered using a three-point scale, the data must be considered as categorical. Compared with continuous data, the steps of longitudinal measurement invariance testing differ with categorical data because the factor loadings and thresholds must be varied in tandem (Muthén \& Asparouhov, 2002). Thus, the measurement invariance testing with categorical data in a longitudinal setting has the same parameter restrictions as a cross-sectional multi-group CFA except the residual correlations across time points (Schroeders \& Wilhelm, 2011). Table 1 summarizes the necessary parameter restrictions in the longitudinal measurement invariance testing procedure (for another approach see Liu et al., 2016). A difference in the CFI of $>.01$ between two consecutive models in invariance testing (e.g., configural and strong measurement invariance models) was considered as a serious deterioration in model fit (Cheung \& Rensvold, 2002). Strong measurement invariance is important to compare the means of latent variables in addition to the correlation and regression coefficients.

Cross-lagged Panel Analysis. A cross-lagged panel analysis with latent variables (Selig \& Little, 2012) was used to estimate the autoregressive effects within and the cross-lagged effects between emotional and behavioral self-regulation. The cross-lagged panel analysis correlated emotional and behavioral regulation at the same time points to test that the cross-lagged effects between emotional and behavioral regulation did not occur because the two variables were related at previous time points (Cole \& Maxwell, 2003). Furthermore, we imposed the most restrictive and appropriate step of measurement invariance that was established in the measurement invariance testing for all cross-lagged models.

\section{Results \\ Descriptive Statistics}

The descriptive statistics of the emotional and behavioral regulation items across the three time points are presented in Table 2. The skewness and kurtosis of all items did not indicate problematic item distributions. Using McDonald's $\omega$ (1999), the reliability of the two latent factors of self-regulation, emotional regulation (age 3: $\omega=.76$; age $5: \omega=.81$; age $7: \omega=.83$ ) and behavioral regulation (age 3: $\omega=.66$; age $5: \omega=.76$; age $7: \omega=.78$ ) were estimated, and both were deemed satisfactory for all time points. Separate measurement models of self-regulation at the three time points were also acceptable: CFIs and TLIs $>.96$ and RMSEAs $<.07$.

\section{One vs. Two-factor Model of Self-regulation}

In order to investigate whether a one- or two-factor model of selfregulation best fits the data, the fit of both longitudinal CFA models, in which the residuals of similar worded items were allowed to correlate across time points, was compared. The result of the unidimensional model did not provide a good fit $\left(\chi^{2}=19,533\right.$, $d f=225, p<.001, \mathrm{CFI}=.891, \mathrm{TLI}=.866$, RMSEA $=.075)$, in contrast to the two-factor model $\left(\chi^{2}=5,683, d f=213, p<.001\right.$, CFI $=.969$, TLI $=.96$, RMSEA $=.040)$. Therefore, the twodimensional model was used in all subsequent analyses.

\section{Measurement Invariance Testing}

The longitudinal invariance testing consisted of a sequence of models with increasingly restrictive model constraints. We examined the model deterioration using CFI and RMSEA because $\chi^{2}$ statistics are overly sensitive when the sample size is large (Steenkamp \& Baumgartner, 1998). In the first step of configural invariance, all of the factor loadings and thresholds were freely estimated; only the residual variances were fixed for identification purpose. The configural model provided an acceptable fit $\left(\chi^{2}=5,683.32, d f=213\right.$, $p<.000$; CFI $=.969$; RMSEA $=.041$ ) showing a similar factor structure over time. In the second step, the factor loadings and thresholds were constrained to be equal across the three time points, and the residual variances of the indicators were freely estimated. This strong measurement invariance did not show a meaningful deterioration in model fit $\left(n=13,593, \chi^{2}=6,406, d f=237\right.$, $p<.001 ; \Delta \mathrm{CFI}=.004, \Delta \mathrm{RMSEA}=.000)$. In the last step, strict measurement invariance, the factor loadings, thresholds, and residual variances were constrained to equality over time. Even the test for strict measurement invariance showed no differences in the model fit indices $\left(n=13,593, \chi^{2}=6,314, d f=253, p<.001\right.$; $\Delta \mathrm{CFI}=-.001, \Delta \mathrm{RMSEA}=-.002)$. Therefore, the instrument was assumed to be strictly measurement invariant across the three time points. Accordingly, all subsequent analysis used a model with (a) residual covariances between identically worded items at different 


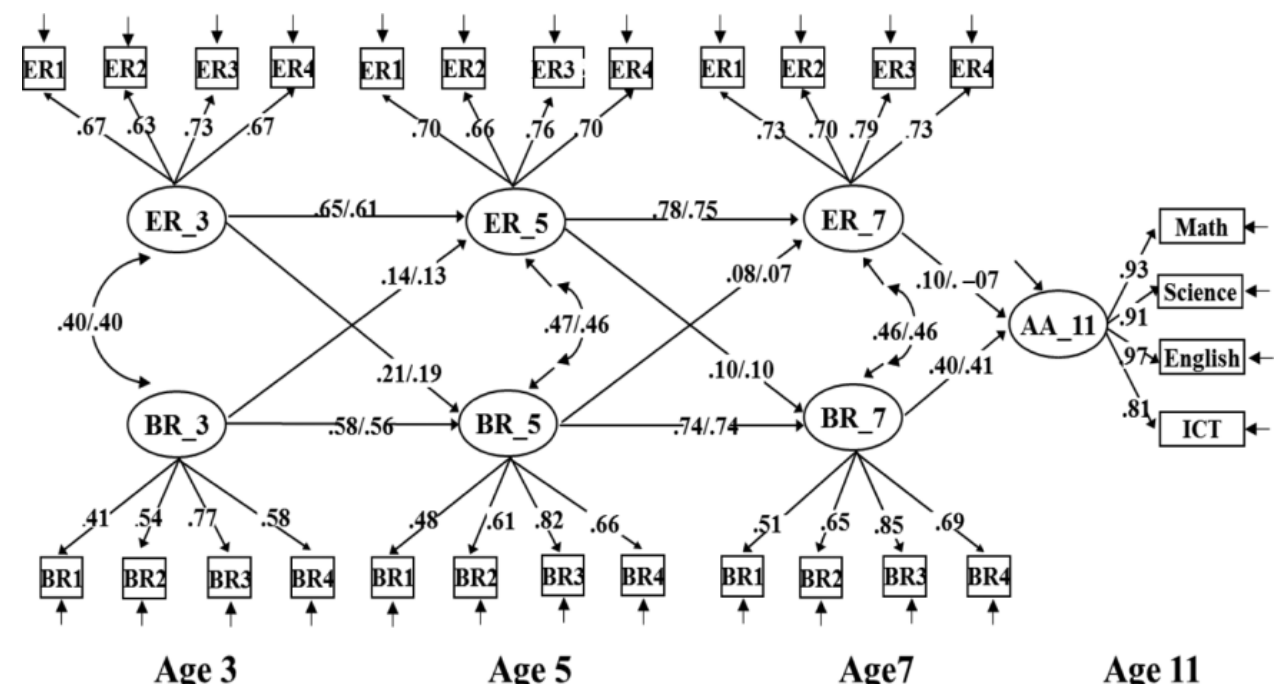

Figure 2. Latent cross-lagged model with and without socio-economic status. Note. $\mathrm{ER}=$ emotional regulation, $\mathrm{BR}=$ behavioral regulation, $\mathrm{AA}=$ academic achievement, numbers in variable labels $(3,5,7, \mathrm{I})$ indicate age of the children in years. All parameters are standardized. The parameters on the left side of the slash are without controlling for SES, on the right controlled for SES. The fit indices of the models without socioeconomic status $\left(n=15,436, \chi^{2}=6,476, d f=35 \mathrm{I}, p<.00 \mathrm{I} ; \mathrm{CFI}=.982\right.$, TLI $=.98 \mathrm{I}$, RMSEA $\left.=.034\right)$ and with $\mathrm{SES}$ $\left(n=15,584, \chi^{2}=8,727, d f=613, p<.001 ; C F I=.97, T L I=.968\right.$, RMSEA $\left.=.029\right)$. Identical items over the three time points were allowed to covary. Strict measurement invariance constraints (equal factor loadings, thresholds, and residual variance) were imposed.

time points and (b) the restrictions necessary for the level of strict measurement invariance: fixed factor loadings, thresholds, and residuals.

\section{Stability and Cross-facets Effects of Emotional and Behavioral Self-regulation}

To examine the stability and cross-facets effects of individual differences in emotional and behavioral regulation from ages 3 to 5-7, cross-lagged models with latent variables were used. The analysis was conducted with and without controlling for the highest SES of the parents at a given time point. A one-factor SES was modeled at a latent level from the three indicators (parent's highest occupation, education, and household income). Overall, the model fit was good for both models: $\mathrm{CFI}=.982, \mathrm{TLI}=.981$, and RMSEA $=.034$ (see also the notes of Figure 2). The robustness of the results was double-checked with 15 multiple imputed datasets using additional variables such as highest educational level, occupational status, and income within a household. However, the results did not differ from the analyses with pairwise present data.

The stability of emotional and behavioral regulation is expressed in the auto-regressive effects of two consecutive time points within a certain facet of self-regulation (e.g., BR_3 $\rightarrow$ BR_5). Individual differences showed moderate stability from ages 3 to 5 for emotional regulation $(\beta=.65)$ and behavioral regulation $(\beta=.57)$, but stability increased from ages 5 to 7 in both facets (emotional regulation: $\beta=.78$; behavioral regulation: $\beta=.74$ ). This finding was confirmed with a $\chi^{2}$-difference test (Satorra, 2000) that evaluated the model fit difference between a restricted (i.e., where the earlier and later stability coefficients are equal) and an unrestricted model, both for emotional $\left(\Delta \chi^{2}(1, N=15,436)=\right.$ $37.67, p<.001)$ and behavioral regulation $\left(\Delta \chi^{2}(1, N=15,436)=\right.$ $14.82, p<.001)$. Taking into account the different measures of family background did not affect the results.
The cross-lagged effects between the constructs provided information about the developmental interplay between emotional and behavioral regulation. Emotional regulation at age 3 significantly predicted individual difference in behavioral regulation at age 5 ( $\beta=.21$, see Figure 2 and Table 3$)$, although this cross-lagged effect was less pronounced from age 5 to 7 . A $\chi^{2}$-difference test $\left(\Delta \chi^{2}(1, N=15,436)=21.28, p<.001\right)$ revealed a difference between the effect of emotional and behavioral regulation (emotional regulation at age $3 \rightarrow$ behavioral regulation at age 5 and emotional regulation at age $5 \rightarrow$ behavioral regulation at age 7 ). Similarly, behavioral regulation showed consistent positive crosslagged effects on emotional regulation, although they were considerably smaller. Behavioral regulation at age 3 predicted emotional regulation at age $5(\beta=.14)$; this effect was even smaller from age 5 to $7(\beta=.09)$. The significance of the difference between the two cross-lagged effects from behavioral to emotional regulation was confirmed by a $\chi^{2}$-difference test $\left(\Delta \chi^{2}(1, N=15,436)=12.14\right.$, $p<.001)$. Taking into account the SES of the family at each time point did not substantially change these results. In summary, both emotional and behavioral self-regulation showed consistent crosslagged effects, whereas the regression weights seemed to be more pronounced for the emotional to behavioral link than behavioral to emotional regulation. In order to test whether the differences were significant, equality constraints on the regression weights (emotional regulation $\rightarrow$ behavioral regulation and behavioral regulation $\rightarrow$ emotional regulation) were imposed at each time point. In terms of the $\chi^{2}$-difference-test between the unconstrained and constrained models, the difference was significant from both ages 3 to 5 and 5 to 7; this finding held true for modeling with and without controlling for SES.

\section{Effects of Self-regulation on Academic Achievement}

One of the major objectives of this study was to quantify the longterm effect of the two facets of self-regulation over the course of 
Table 3. Stability and Cross-Lagged Effects of Emotional and Behavioral Regulation, and Predictions on Academic Achievement.

\begin{tabular}{|c|c|c|c|c|}
\hline & \multicolumn{2}{|c|}{$\begin{array}{c}\text { Without } \\
\text { socioeconomic } \\
\text { status }\end{array}$} & \multicolumn{2}{|c|}{$\begin{array}{c}\text { With } \\
\text { socioeconomic } \\
\text { status }\end{array}$} \\
\hline & $\beta$ & {$[95 \% \mathrm{Cl}]$} & $\beta$ & {$[95 \% \mathrm{Cl}]$} \\
\hline \multicolumn{5}{|l|}{ Stability } \\
\hline $\begin{array}{l}\text { Emotional regulation (age 3) } \rightarrow \\
\quad \text { Emotional regulation (age } 5 \text { ) }\end{array}$ & .65 & {$[.63, .67]$} & .61 & {$[.59, .63]$} \\
\hline $\begin{array}{l}\text { Emotional regulation (age } 5 \text { ) } \rightarrow \\
\text { Emotional regulation (age 7) }\end{array}$ & .78 & {$[.76, .80]$} & .75 & {$[.72, .78]$} \\
\hline $\begin{array}{l}\text { Behavioral regulation (age } 3 \text { ) } \rightarrow \\
\quad \text { Behavioral regulation (age 5) }\end{array}$ & .58 & {$[.55, .61]$} & .56 & {$[.53, .59]$} \\
\hline $\begin{array}{l}\text { Behavioral regulation (age 5) } \rightarrow \\
\quad \text { Behavioral regulation (age 7) }\end{array}$ & .74 & {$[.71, .77]$} & .74 & {$[.71, .77]$} \\
\hline \multicolumn{5}{|l|}{ Cross-lagged effects } \\
\hline $\begin{array}{l}\text { Emotional regulation (age } 3 \text { ) } \rightarrow \\
\quad \text { Behavioral regulation (age 5) }\end{array}$ & .21 & {$[.18, .24]$} & .19 & {$[.16, .22]$} \\
\hline $\begin{array}{l}\text { Emotional regulation (age } 5 \text { ) } \rightarrow \\
\quad \text { Behavioral regulation (age } 7 \text { ) }\end{array}$ & .10 & {$[.07, .13]$} & .10 & {$[.06, .14]$} \\
\hline $\begin{array}{l}\text { Behavioral regulation (age } 3 \text { ) } \rightarrow \\
\quad \text { Emotional regulation (age 5) }\end{array}$ & .14 & {$[.11, .17]$} & .13 & {$[.10, .15]$} \\
\hline $\begin{array}{l}\text { Behavioral regulation (age 5) } \rightarrow \\
\quad \text { Emotional regulation (age 7) }\end{array}$ & .08 & {$[.05, .11]$} & .07 & {$[.04, .10]$} \\
\hline \multicolumn{5}{|l|}{ Effects on academic achievement } \\
\hline $\begin{array}{l}\text { Emotional regulation (age 7) } \rightarrow \\
\quad \text { Academic achievement }(\text { age II) }\end{array}$ & .09 & {$[.04, .14]$} & -.07 & {$[-.12,02]$} \\
\hline $\begin{array}{l}\text { Behavioral regulation (age 7) } \rightarrow \\
\quad \text { Academic achievement (age II) }\end{array}$ & .40 & {$[.35, .45]$} & .41 & {$[.36, .46]$} \\
\hline \multicolumn{5}{|l|}{ Indirect effects } \\
\hline $\begin{array}{l}\text { Emotional regulation (age } 5 \text { ) } \rightarrow \\
\quad \text { Academic achievement }(\text { age } \mathrm{II})\end{array}$ & .04 & {$[.03,0.05]$} & .04 & {$[.02, .06]$} \\
\hline
\end{tabular}

Note. Strict measurement invariance was imposed. Without socioeconomic status $\left(n=15,436, \chi^{2}=6,476, d f=35 \mathrm{I}, p<.00 \mathrm{I} ; \mathrm{CFI}=.982, \mathrm{TLI}=.98 \mathrm{I}\right.$, RMSEA $=$ $.034)$ and with socioeconomic status $\left(n=15,584, \chi^{2}=8,727, d f=613, p<.001\right.$; $\mathrm{CFI}=.97, \mathrm{TLI}=.968, \mathrm{RMSEA}=.029)$.

early childhood on academic achievement at the end of primary school. Therefore, we predicted teacher evaluations of academic achievement across four subjects at age 11 (when most students are in their final year of primary school) using emotional and behavioral self-regulation at age 7 (when students are largely enrolled in the second grade). On the one hand, the behavioral regulation of the participants at age 7 substantially predicted academic achievement at age $11(\beta=.40)$, and this effect remained significant after controlling for SES. On the other hand, only a small direct effect was found for emotional selfregulation $(\beta=.09)$, which became negligible when accounting for SES (also see Table 1 in the online supplement). The indirect effect of emotional regulation at age 5, which was calculated as suggested by Baron and Kenny (1986), on academic achievement via behavioral regulation at age 7 was very small $(\beta=.04)$ after controlling for SES.

\section{Discussion}

In the literature on the development of self-regulation, no consensus exists regarding whether self-regulation is a uni- or a multidimensional construct. Some researchers argue that self-regulation is a domain-general construct without clear differentiation among its different facets. In contrast to Raffaelli et al. (2005) who claimed empirical support for the unidimensional perspective via a longitudinal analysis at three time points $(4-5,8-9$, and $12-13$ years), the present study suggested that self-regulation is a multifaceted construct and that emotional and behavioral self-regulation show unique developmental patterns. Notably, although Raffaelli et al. (2005) interpreted their results as evidence for a uni-dimensional structure of self-regulation, the results are much in line with the present study, except for early childhood. The present study also replicated previous cross-sectional (e.g., Kalpidou et al., 2004; Schields et al., 1994) and longitudinal studies (e.g., Hammer, Melhuish, \& Howard, 2015).

From a methodological perspective, we used longitudinal measurement invariance testing to show that the two-dimensional measurement model of self-regulation had strict measurement invariance; thus, the same construct was assessed using precisely the same measurement at all three time points (Little et al., 2007; Selig \& Little, 2012). This study is also one of the first applications of longitudinal measurement invariance testing using categorical data (see also Liu et al., 2016). Compared with multi-group CFA, which treats different time points as different groups, longitudinal measurement invariance testing was deemed to be more appropriate because it allows for correlations between identical items across time points. Given the growing availability of large-scale longitudinal education datasets, these findings hopefully provide some guidance regarding how to study trajectories while establishing the comparability of the scales over time. Testing for measurement invariance is essential in order to establish that the differences can be attributed to changes in the underlining construct rather than to changes in the measurement.

The present study showed that emotional and behavioral selfregulation mutually affect each other during early childhood. This finding is in line with previous theoretical considerations (Blair, 2002; Cicchetti \& Toth, 1998); however, this relationship has not been thoroughly investigated empirically. From a neurobiological perspective, this mutual interdependence can be attributed to the development of the neural interconnectivity between the different brain areas associated with emotional (the amygdala in the limbic system) and behavioral (the prefrontal cortex) regulation. Blair (2002) stated that a change in one system of self-regulation can shape the development of the other (also see Cicchetti \& Tucker, 1994; Schields et al., 1994). This condition implies that when children learn how to regulate their emotional state, they can more easily regulate their behavior; similarly, the development of behavioral self-regulation should foster the ability to regulate emotions more flexibly and efficiently (Campos et al., 2004; Carver \& Scheier, 2012; Eisenberg \& Spinrad, 2004). Furthermore, the results of the present study indicated that the effect of emotional selfregulation on behavioral self-regulation was stronger than that in the opposite direction, especially from ages 3 to 5 . Theoretically, this effect might be because of the "developmental maturational primacy" of the brain areas that control emotional regulation (Blair, 2002). However, the comparison of cross-facet effects at a later time point (i.e., between ER_5 $\rightarrow$ BR_7 and BR_5 $\rightarrow$ ER_7) did not yield a significant difference, which might be because of an incremental change in the stability of both emotional and behavioral regulation from ages 5 to 7 .

We found that emotional and behavioral regulation were fairly stable constructs, supporting previous findings (Eisenberg et al., 2010; Murphy et al., 1999; Raffaelli et al., 2005). From a developmental perspective, the increasing stability in self-regulation 
observed in the present dataset matches previous research on a related construct: executive function (Zelazo \& Carlson, 2012). This stage is key for the improvement of children's selfregulatory skills through observation and experience in the transition from home to a formal preschool environment (Bandura, 1991). Importantly, however, stability (i.e., the variancecovariance structure) does not mean that self-regulation (i.e., mean structure) does not improve. A growing body of literature has shown the malleability of self-regulation during childhood, using more restrictive methods such as randomized control trials (Blair, 2016; Blair \& Raver, 2015; Schmitt et al., 2015).

The effect of the early development of self-regulation on the later academic achievement of children is well documented (Gestsdottir et al., 2014; McClelland et al., 2007). The present study adds evidence showing that the development of selfregulation during childhood positively contributes to the academic achievement of children at the end of primary school to a considerable degree. In particular, behavioral self-regulation displayed a substantial effect $(\beta=.40)$. The relationship did not change even after controlling for SES (see Table 3), even though we expected the reduction reported in a recent meta-analysis (Jacob \& Parkinson, 2015) because SES affects academic achievement (Lengua et al., 2015; Raikes, Robinson, Bradley, Raikes, \& Ayoub, 2007) and self-regulation (Lengua et al., 2015). Given that the gap between the two time points (ages 7 and 11), the different raters (parents and teachers) and the fact that the predictor and criterion are distinct constructs, this effect is surprisingly large. One interpretation is that children who are more capable of regulating their behavior can also focus and control their learning process more efficiently (Blair, 2002; Blair \& Raver, 2015; McClelland et al., 2007). Additional evidence can be found in recent longitudinal studies that have reported similar results (e.g., Gestsdottir et al., 2014; Ng et al., 2015). One alternative explanation is that because academic achievement was measured via teacher judgments (and not a standardized achievement test), behaviorally well-regulated or well-adapted children also tended to receive higher teacher ratings. In other words, teacher evaluations are at least partially based on conduct within the classroom (Bennett, Gottesman, Rock, \& Cerullo, 1993). In fact, both performance and conduct are important in grading and are difficult to disentangle because behavioral regulation and adaption to social standards is also part of the school system. Furthermore, directly observable behavior provides easily assessable and relevant cues for teachers' evaluations of children's performances (Funder, 1995). Emotional regulation had a small direct effect on academic achievement $(\beta=.10)$ that became negligible after controlling for SES. This finding might simply be because emotional self-regulation was correlated more strongly with SES than behavioral self-regulation (see Table OS-1 in the online supplement). In addition, behavioral regulation might play a moderating role in this relationship (Valiente et al., 2010). However, emotional regulation had an indirect effect on academic achievement through behavioral self-regulation as predicted previously (Howse et al., 2003; Trentacosta \& Izard, 2007). In other words, optimal emotional arousal seems to promote attention, problem solving, and behavioral regulation (Blair, 2002; $\mathrm{Ng}$ et al., 2015). The mediating role that behavioral selfregulation plays in the relationship between it and emotional regulation found in the present study adds to the existing debate regarding how the facets of self-regulation and academic achievement are associated.

\section{Limitations and Implications for Future Directions}

Although the study supported the neurobiological approach, in the present study longitudinal questionnaire data is analyzed rather than the neurobiology of children, thus, definite statements in this respect cannot be made. The maturational aspect of neurobiology might be an important subject of future research. In addition, parental judgment can be biased when rating the emotional and behavioral regulation of their own children; however, several studies have supported the accuracy of their judgments (e.g., McClelland, Acock, Piccinin, Rhea, \& Stallings, 2013). Similarly, teacher evaluations were used to measure academic achievement rather than standardized test scores. Therefore, teacher evaluations of academic achievement might be biased by different factors (e.g., the perceived similarity in the personalities of students and teachers; Rausch, Karing, Dörfler, \& Artelt, 2015). However, studies have also failed to find significant differences between teacher ratings and direct assessments (Allan, Hume, Allan, Farrington, \& Lonigan, 2014). Finally, previous achievement and IQ were not controlled; these variables are potential confounds in the association between self-regulation and academic achievement (Jacob \& Parkinson, 2015)

The findings of the present study have theoretical and practical implications. From a theoretical perspective, the results emphasize the neurobiological assumption regarding the importance of the child's characteristics, beyond the traditional maturational view, in shaping their self-regulatory skills, which is also essential for academic achievement. In practical terms, because the facets of self-regulation are mutually dependent, intervention programs that aim to improve the academic achievement of children through self-regulation should incorporate activities that promote both emotional and behavioral regulation in the classroom and the home environment instead of focusing on a single facet. Correspondingly, future studies on the association between selfregulation and academic achievement should study different facets of self-regulation in concert. In this sense, including metacognition as an important third facet of self-regulation is a logical extension in order to gain a more comprehensive picture on the mutual development of self-regulation. Finally, we encourage the use of longitudinal study designs (or restrictive designs such as randomized control trials) and the employment of psychometrically sound measurements.

\section{Funding}

The authors declared receipt of the following financial support for the research, authorship, and/or publication of this article: This work was supported by the Bamberg Graduate School of Social Sciences which is funded by the German Research Foundation (DFG) under the German Excellence Initiative (GSC1024).

\section{Supplemental material}

Supplementary material for this article is available online.

\section{References}

Allan, N. P., Hume, L. E., Allan, D. M., Farrington, A. L., \& Lonigan, C. J. (2014). Relations between inhibitory control and the development of academic skills in preschool and kindergarten: A meta-analysis. Developmental Psychology, 50, 2368-2379. doi:10.1037/ a0037493 
Bandura, A. (1991). Social cognitive theory of self-regulation. Organizational Behavior and Human Decision Process, 50, 248-287.

Baron, R. M., \& Kenny, D. A. (1986). The moderator-mediator variable distinction in social psychological research: Conceptual, strategic, and statistical considerations. Journal of Personality and Social Psychology, 51, 1173-1182.

Beauducel, A., \& Herzberg, P. Y. (2006). On the performance of maximum likelihood versus means and variance adjusted weighted least squares estimation in CFA. Structural Equation Modeling: A Multidisciplinary Journal, 13, 186-203. doi:10.1207/ s15328007sem1302_2

Bennett, R. E., Gottesman, R. L., Rock, D. A., \& Cerullo, F. (1993). Influence of behavior perceptions and gender on teachers' judgments of students' academic skill. Journal of Educational Psychology, 85, 347-356. doi:10.1037/0022-0663.85.2.347

Berkman, E. T., Graham, A. M., \& Fisher, P. A. (2012). Training self-control: A domain-general translational neuroscience approach. Child Development Perspectives, 6, 374-384. doi:10.1111/ j.1750-8606.2012.00248.x

Blair, C. (2002). School readiness: Integrating cognition and emotion in a neurobiological conceptualization of children's functioning at school entry. American Psychologist, 57, 111-127. doi:10.1037/ 0003-066X.57.2.111

Blair, C. (2016). Developmental science and executive function. Current Directions in Psychological Science, 25, 3-7. doi:10. $1177 / 0963721415622634$

Blair, C., \& Diamond, A. (2008). Biological processes in prevention and intervention: The promotion of self-regulation as a means of preventing school failure. Development and Psychopathology, 20, 899-911. doi:10.1017/S0954579408000436

Blair, C., \& Raver, C. C. (2012). Child development in the context of adversity: Experiential canalization of brain and behavior. American Psychologist, 67, 309-318. doi.org/10.1037/a0027493

Blair, C., \& Raver, C. C. (2015). School readiness and self-regulation: A developmental psychobiological approach. Annual Review of Psychology, 66, 711-731. doi:10.1146/annurev-psych-010814-015221

Campos, J. J., Frankel, C. B., \& Camras, L. (2004). On the nature of emotion regulation. Child Development, 75, 377-394. doi:10.1111/ j.1467-8624.2004.00681.x

Carver, C. S., \& Scheier, M. F. (2012). Cybernetic control processes and the self-regulation of behavior. In R. M. Ryan (Ed.), The Oxford Handbook of Human Motivation (pp. 28-42). Oxford, UK: Oxford University Press.

Cheung, G. W., \& Rensvold, R. B. (2002). Evaluating goodness-of-fit indexes for testing measurement invariance. Structural Equation Modeling: A Multidisciplinary Journal, 9, 233-255. doi:10.1207/ S15328007SEM0902_5

Cicchetti, D., \& Toth, S. L. (1998). Perspectives on research and practice in developmental psychopathology. In W. Damon, I. E. Sigel \& K. A. Renninger (Eds.), Handbook of child psychology, Vol 4: Child psychology in practice (5th ed., pp. 479-583). Hoboken, NJ: John Wiley \& Sons.

Cicchetti, D., \& Tucker, D. (1994). Development and self-regulatory structures of the mind. Development and Psychopathology, 6, 533-549.

Cole, D. A., \& Maxwell, S. E. (2003). Testing mediational models with longitudinal data: Questions and tips in the use of structural equation modeling. Journal of Abnormal Psychology, 112, 558-577. doi:10.1037/0021-843X.112.4.558

Cole, P. M., Martin, S. E., \& Dennis, T. A. (2004). Emotion regulation as a scientific construct: Methodological challenges and directions for child development research. Child Development, 75, 317-333. doi:10.1111/j.1467-8624.2004.00673.x

Demetriou, A. (2000). Organization and development of selfunderstanding and self-regulation. In M. Boekaerts, P. R. Pintrich \& M. Zeidner (Eds.), Handbook of self-regulation (pp. 209-251). New York: Academic Press.

Diaz, A., Eisenberg, N., Valiente, C., Van Schyndel, S., Spinrad, T. L., Berger, R., ... Southworth, J. (2015). Relations of positive and negative expressivity and effortful control to kindergarteners' student-teacher relationship, academic engagement, and externalizing problems at school. Journal of Research in Personality. doi:10. 1016/j.jrp.2015.11.002.

Eisenberg, N., Chang, L., Ma, Y., \& Huang, X. (2009). Relations of parenting style to Chinese children's effortful control, ego resilience, and maladjustment. Development and Psychopathology, 21, 455-477. doi:10.1017/S095457940900025X

Eisenberg, N., \& Spinrad, T. L. (2004). Emotion-related regulation: Sharpening the definition. Child Development, 75, 334-339. doi: 10.1111/j.1467-8624.2004.00674.x

Eisenberg, N., Spinrad, T. L., \& Eggum, N. D. (2010). Emotion-related self-regulation and its relation to children's maladjustment. Annual Review of Clinical Psychology, 6, 495-525. doi:10.1146/annurev. clinpsy. 121208.131208

Flavell, J. H. (1979). Metacognition and cognitive monitoring: A new area of cognitive-developmental inquiry. American Psychologist, 34, 906-911.

Funder, D. C. (1995). On the accuracy of personality judgment: A realistic approach. Psychological Review, 102, 652-670. doi:10.1037/ 0033-295X.102.4.652

Gestsdottir, S., von Suchodoletz, A., Wanless, S. B., Hubert, B., Guimard, P., Birgisdottir, F., .. McClelland, M. (2014). Early behavioral self-regulation, academic achievement, and gender: Longitudinal findings from France, Germany, and Iceland. Applied Developmental Science, 18, 90-109. doi:10.1080/10888691.2014. 894870

Goodman, A., \& Goodman, R. (2009). Strengths and difficulties questionnaire as a dimensional measure of child mental health. Journal of the American Academy of Child \& Adolescent Psychiatry, 48, 400-403. doi:10.1097/CHI.0b013e3181985068

Hammer, D., Melhuish, E., \& Howard, S. (2015). The nature and importance of self-regulation in early childhood: Factor structure and predictive validity (p. 41). Abstract presented at the 17th European Conference on Developmental Psychology, Braga, Portugal.

Hansen, K. (2014). Millennium cohort study first, second, third, fourth and fifth surveys: A guide to the datasets, (8th ed.). London: Centre for Longitudinal Studies, Institute of Education, University of London.

Heatherton, T. F. (2011). Neuroscience of self and self-regulation. Annual Review of Psychology, 62, 363-390. doi:10.1146/annurev. psych.121208.131616

Hogan, A. E., Scott, K. G., \& Bauer, C. R. (1992). The adaptive social behavior inventory (Asbi): A new assessment of social competence in high-risk three-year-olds. Journal of Psychoeducational Assessment, 10, 230-239. doi:10.1177/073428299201000303

Howse, R. B., Calkins, S. D., Anastopoulos, A. D., Keane, S. P., \& Shelton, T. L. (2003). Regulatory contributors to children's kindergarten achievement. Early Education \& Development, 14, 101-120. doi:10.1207/s15566935eed1401_7

Hu, L., \& Bentler, P. M. (1999). Cutoff criteria for fit indexes in covariance structure analysis: Conventional criteria versus new 
alternatives. Structural Equation Modeling: A Multidisciplinary Journal, 6, 1-55. doi:10.1080/10705519909540118

Jacob, R., \& Parkinson, J. (2015). The potential for school-based interventions that target executive function to improve academic achievement: A Review. Review of Educational Research, 85, 512-552. doi:10.3102/0034654314561338

Johnson, M. H. (2011). Interactive Specialization: A domain-general framework for human functional brain development? Developmental Cognitive Neuroscience, 1, 7-21. doi:10.1016/j.den.2010.07.003

Kalpidou, M. D., Power, T. G., Cherry, K. E., \& Gottfried, N. W. (2004). Regulation of emotion and behavior among 3- and 5-year-olds. The Journal of General Psychology, 131, 159-178. doi:10.3200/GENP.131.2.159-180

Kopp, C. B. (1982). Antecedents of self-regulation: A developmental perspective. Developmental Psychology, 18, 199-214. doi.org/10. 1037/0012-1649.18.2.199.

Lengua, L. J., Moran, L., Zalewski, M., Ruberry, E., Kiff, C., \& Thompson, S. (2015). Relations of growth in effortful control to family income, cumulative risk, and adjustment in preschool-age children. Journal of Abnormal Child Psychology, 43, 705-720. doi:10.1007/ s10802-014-9941-2

Little, T. D., Preacher, K. J., Selig, J. P., \& Card, N. A. (2007). New developments in latent variable panel analyses of longitudinal data. International Journal of Behavioral Development, 31, 357-365. doi:10.1177/0165025407077757

Liu, Y., Millsap, R. E., West, S. G., Tein, J.-Y., Tanaka, R., \& Grimm, K. J. (2016). Testing measurement invariance in longitudinal data with ordered-categorical measures. Psychological Methods. doi: 10.1037/met0000075

McClelland, M. M., Acock, A. C., Piccinin, A., Rhea, S. A., \& Stallings, M. C. (2013). Relations between preschool attention span-persistence and age 25 educational outcomes. Early Childhood Research Quarterly, 28, 314-324.

McClelland, M. M., Cameron, C. E., Connor, C. M., Farris, C. L., Jewkes, A. M., \& Morrison, F. J. (2007). Links between behavioral regulation and preschoolers' literacy, vocabulary, and math skills. Developmental Psychology, 43, 947-959. doi:10.1037/0012-1649. 43.4.947

McClelland, M. M., Ponitz, C. C., Messersmith, E. E., \& Tominey, S. (2010). Self-regulation: Integration of cognition and emotion. In W. F. Overton \& R. M. Lerner (Eds.), The handbook of life-span development (pp. 509-555). Hoboken, NJ: Wiley.

McDonald, R. P. (1999). Test theory: A unified treatment. Mahwah, NJ: Erlbaum Associates.

Melhuish, E., Hanna, K., Quinn, L., Sylva, K., Siraj-Blatchford, I., Sammons, P., \& Taggart, B. (2004). The effective pre-school provision northern Ireland (EPPNI) project: Technical Paper 11: Pre-school experience and social/behavioural development at the end of year 3 of primary school. Belfast: Stranmillis Press.

Muraven, M., \& Baumeister, R. F. (2000). Self-regulation and depletion of limited resources: Does self-control resemble a muscle? Psychological Bulletin, 126, 247-259. doi:10.1037/0033-2909. 126.2.247

Murphy, B. C., Eisenberg, N., Fabes, R. A., Shepard, S., \& Guthrie, I. K. (1999). Consistency and change in children's emotionality and regulation: A longitudinal study. Merrill-Palmer Quarterly, 45, 413-444.

Muthén, B., \& Asparouhov, T. (2002). Latent variable analysis with categorical outcomes: Multiple-group and growth modeling in Mplus. Mplus Web Notes, 4, 1-22.
Ng, F. F., Tamis-LeMonda, C., Yoshikawa, H., \& Sze, I. N. (2015). Inhibitory control in preschool predicts early math skills in first grade: Evidence from an ethnically diverse sample. International Journal of Behavioral Development, 39, 139-149. doi:10.1177/ 0165025414538558

Plewis, I. (2007). The millennium cohort study: Technical report on sampling. London: Centre for Longitudinal Studies, Institute of Education, University of London.

R Development Core Team. (2011). R: A language and environment for statistical computing (Version 2.13.2). Vienna: R Foundation for Statistical Computing. Retrieved from http://www.R-project. org/

Raffaelli, M., Crockett, L. J., \& Shen, Y.-L. (2005). Developmental stability and change in self-regulation from childhood to adolescence. The Journal of Genetic Psychology, 166, 54-76. doi:10. 3200/GNTP.166.1.54-76

Raikes, H. A., Robinson, J. L., Bradley, R. H., Raikes, H. H., \& Ayoub, C. C. (2007). Developmental trends in self-regulation among low-income toddlers. Social Development, 16, 128-149. doi:10. 1111/j.1467-9507.2007.00375.x

Rausch, T., Karing, C., Dörfler, T., \& Artelt, C. (2015). Personality similarity between teachers and their students influences teacher judgement of student achievement. Educational Psychology. doi:10.1080/01443410.2014.998629

Raver, C. C., Blair, C., \& Willoughby, M., \& Family Life Project Key Investigators. (2013). Poverty as a predictor of 4-year-olds' executive function: New perspectives on models of differential susceptibility. Developmental Psychology, 49, 292-304. doi:10.1037/ a0028343

Rhemtulla, M., Brosseau-Liard, P. É., \& Savalei, V. (2012). When can categorical variables be treated as continuous? A comparison of robust continuous and categorical SEM estimation methods under suboptimal conditions. Psychological Methods, 17, 354-373. doi: 10.1037/a0029315

Rose, D., Pevalin, D. J., \& O'Reilly, K. (2005). The national statistics socio-economic classification: Origins, development and use. London, UK: Palgrave Macmillan.

Rosseel, Y. (2012). lavaan: An R package for structural equation modeling. Journal of Statistical Software, 48, 1-36. doi:10.18637/jss. v048.i02

Rothbart, M. K., \& Bates, J. E. (2006). Temperament. In W. Damon \& R. M. Lerner (Eds.), Handbook of child psychology. Hoboken, NJ: John Wiley \& Sons.

Satorra, A. (2000). Scaled and adjusted restricted tests in multi-sample analysis of moment structures. New York, NY: Springer.

Sammons, P., Sylva, K., Melhuish, E., Siraj-Blatchford, I., Taggart, B., Elliot, K., \& Marsh, A. (2004). The effective provision of pre-school education (EPPE) project: The continuing effects of pre-school education at age 7 years. London, UK: University of London.

Schields, A. M., Cicchetti, D., \& Ryan, R. M. (1994). The development of emotional and behavioral self-regulation and social competence among maltreated school-age children. Development and Psychopathology, 6, 57-75.

Schmitt, S. A., McClelland, M. M., Tominey, S. L., \& Acock, A. C. (2015). Strengthening school readiness for Head Start children: Evaluation of a self-regulation intervention. Early Childhood Research Quarterly, 30, 20-31. doi:10.1016/j.ecresq. 2014.08.001

Schroeders, U., \& Wilhelm, O. (2011). Equivalence of reading and listening comprehension across test media. Educational and 
Psychological Measurement, 71, 849-869. doi:10.1177/ 0013164410391468

Selig, J. P., \& Little, T. D. (2012). Autoregressive and cross-lagged panel analysis for longitudinal data. In B. P. Laursen, T. D. Little \& N. A. Card (Eds.), Handbook of developmental research methods (pp. 265-278). New York, NY: Guilford Press.

Steenkamp, J. E. M., \& Baumgartner, H. (1998). Assessing measurement invariance in cross-national consumer research. Journal of Consumer Research, 25, 78-107. doi:10.1086/209528

Thompson, R. A. (1994). Emotional regulation: A theme in search of definition. Monographs of the Society for Research in Child Development, 59, 25-52. doi:10.1111/j.1540-5834.1994.tb01276.x

Trentacosta, C. J., \& Izard, C. E. (2007). Kindergarten children's emotion competence as a predictor of their academic competence in first grade. Emotion, 7, 77-88. doi:10.1037/1528-3542.7.1.77

Valiente, C., Lemery-Chalfant, K., \& Castro, K. S. (2007). Children's effortful control and academic competence: Mediation through school liking. Merrill-Palmer Quarterly, 53, 1-25.
Valiente, C., Lemery-Chalfant, K., \& Swanson, J. (2010). Prediction of kindergartners' academic achievement from their effortful control and emotionality: Evidence for direct and moderated relations. Journal of Educational Psychology, 102, 550-560. doi:10.1037/ a0018992

Valiente, C., Lemery-Chalfant, K., Swanson, J., \& Reiser, M. (2008). Prediction of children's academic competence from their effortful control, relationships, and classroom participation. Journal of Educational Psychology, 100, 67-77. doi:10.1037/0022-0663.100.1.67

Vernon-Feagans, L., Willoughby, M., \& Garrett-Peters, P., \& The Family Life Project Key Investigators. (2016). Predictors of behavioral regulation in kindergarten: Household chaos, parenting, and early executive functions. Developmental Psychology, 52, 430-441. doi: $10.1037 / \operatorname{dev} 0000087$

Zelazo, P. D., \& Carlson, S. M. (2012). Hot and cool executive function in childhood and adolescence: Development and plasticity. Child Development Perspectives, 6, 354-360. doi:10.1111/j.1750-8606. 2012.00246.x 